\title{
Electronic measuring system design for photovoltaic panels analysis
}

\author{
Krastin Yordanov ${ }^{1, *}$, Iliya Hadzhidimov ${ }^{1}$, and Penka Zlateva ${ }^{1}$ \\ ${ }^{1}$ TU Varna, Department of Thermal Engineering, 1 Studentska Str., 9010 Varna, Bulgaria
}

\begin{abstract}
The article presents the design and manufacture of an electronic measuring system based on an ESP32 microcontroller equipped with LORA E32 wireless data transceivers, a SD card for data recording and a computer with application for photovoltaic panels testing. Under environmental conditions the system has been experimentally tested to determine the efficiency of photovoltaic panels, which depends primarily on solar radiation and ambient parameters. In addition, the current, voltage and surface temperatures on the back side of the panels have been measured. The measuring sensors are selected in order to achieve the goal set, as well the durability of the system. The rising of the surface temperature of the photovoltaic panels have a significant effect on module's efficiency, increasing the risk of losing energy production. In the experimental study, temperature, solar radiation, current and voltage have been measured to refine the effect on a monocrystalline and polycrystalline structure of photovoltaic panel. The test has been performed on the experimental field of the Technical University of Varna, Bulgaria. Also, the ambient meteorological parameters during the experiment are reported by a weather station mounted on the experimental field, which transmits data online in the global meteorological database Wunderground with name IVARNA50.
\end{abstract}

\section{Introduction}

The recent years have seen an increasing need for the use of solar energy, dictated by the gradual depletion of conventional energy resources, such oil, natural gas and coal, on the one hand, and by environmental protection considerations, on the other hand. At the end of the 20th century, scientists from all over the world focused their efforts on the development and implementation of technologies for energy production from so-called "renewable sources" [1-3]. The major part of the endeavors related to renewable energy sources is aimed at the development of converters of solar energy into electricity, i.e. photovoltaic panels (PV) [4].

Over the past years, the photovoltaic panels market has been developing and expanding at increasing rates. The beginning of the 21 st century saw the worldwide installation of power plants of a new capacity exceeding $3600 \mathrm{MWp}[5,6]$. When installing a photovoltaic system, the photovoltaic panels account for about half of the investment. They are an important part of the photovoltaic system and their financing depends primarily on their energy performance. $[7,8]$ Photovoltaic panels still feature relatively low conversion efficiencies.

\footnotetext{
* Corresponding author: krastin_yordanov@tu-varna.bg
} 
Thus, when designing PV systems, it is very important that the panel control ensures maximum power delivery (Maximum Power Point Tracker - MPPT). The power varies depending on the change of solar radiation and the temperature of the module, which differ for the different times of the day and depend on the environmental parameters. The implementation of the MPPT processes requires various methods, which are of different complexity depending on the results expected $[9,10]$. With simpler interference and observation methods, the point of maximum power is determined by directly controlling the power calculated from the measurements of the current and the voltage of the module as an initial value. As technology advances, fuzzy logic and controllers are increasingly used in the MPPT process. Their main advantage is that mathematical models are not required to control the power. High accuracy is rather achieved through using a significant amount of information from preliminary research to determine the functions of affiliation of linguistic terms, the base rules, etc. [11-13]

Other methods for tracking the MPP point with their respective advantages and disadvantages are also employed. Some of them are based on measuring the solar radiation and the panel temperature, while others use voltage and current [14-16]. Only a few of the methods take into account the multiple local power peaks obtained as a result of partial shading of the PV panels, which can be a real obstacle to the MPPT functionality [17-19]. When it reaches and works at a local maximum, significant energy loss occur due to the tracking of the local, instead of the global MPP, as experts claim. However, some of the methods require additional initial steps to avoid this set of local maxima and achieve proximity to the true MPP $[20,21]$.

The present study aims at determining the efficiency of photovoltaic panels, which depends primarily on the global solar radiation density and environmental parameters. A measuring electronic system is designed and manufactured based on a microcontroller with wireless transmission, reception, and recording of data on an SD card and a computer with an application for photovoltaic panel analysis, and experimental testing and testing in a real working environment are conducted.

\section{Methods and materials employed}

\subsection{Methods}

The choice of measurement methods involves meteorological approach to the processing of the results obtained from the electronic measuring system sensors installed, i.e. the calculation of the average value $\bar{x}$ of the measurements:

$$
\bar{x}=\frac{\sum_{i=1}^{n} x_{i}}{n}
$$

where: where:

$x_{i}-$ the value measured in every one second;

$n$ - number of measurements for the selected period.

This averages the result of $n$ measurements and facilitates their processing.

The measured physical quantities that will participate in the system design are the temperature $t$, solar radiation $S R$, voltage $U$, current $I$, ambient temperature $t_{a m b}$, relative humidity $R H$ and barometric pressure $P_{b}$. These values are combined with microcontroller ESP32.

For measuring the temperature of the photovoltaic panels' inside, a digital temperature sensor DS18B20 of the company MAXIM with a range of temperature measurement from $55^{\circ} \mathrm{C}$ to $+125^{\circ} \mathrm{C}$ is chosen. The measurement accuracy of $0,5^{\circ} \mathrm{C}$ is in the range from -10 to 
$+85^{\circ} \mathrm{C}$. It has a 9 to 12 -bit conversion resolution and various functions for monitoring temperatures in degrees Celsius $\left({ }^{\circ} \mathrm{C}\right)$. One of the good features of the selected sensor is the opportunity to combine up to 1023 sensors connected to one wire, depending on the microcontroller resolution.

The solar radiation contacting photovoltaic panels surface is measured by a BPW34 photodiode, in which the incident coming sunlight induce a direct current. It can be measured with the ADC converter of the measuring module. To obtain the solar radiation SR as a quantity, the following equation is used:

$$
S R=\frac{U_{s} \cdot U_{i n} \cdot 1000}{4095} \cdot K_{S R}, W / m^{2}
$$

where:

$U_{S}$ - sensor voltage;

$U_{\text {in }}$ - supply voltage $3,3 \mathrm{~V}$;

4095 - 12-bit rate of the microcontroller's ADC converter;

$K_{S R}$ - conversion factor, experimentally determined.

The current and voltage produced by the photovoltaic panels are measured with a precision current amplifier MAX471 produced by MAXIM with a measuring range up to 36 $\mathrm{V}$ and a current of $3 \mathrm{~A}$. The amplifier provides a linear dependence of the measured quantities by the following equations:

Voltage measurement:

$$
U=\frac{U_{s} \cdot U_{i n} \cdot 0,1875}{1000}, V
$$

Current measurement:

$$
I=\frac{U_{s} \cdot 0,1875}{1000}, \mathrm{~A},
$$

where:

$U_{s}-$ sensor voltage, $\mathrm{V}$;

$U_{\text {in }}-$ input voltage $4,98 \mathrm{~V}$;

0,1875 - 16-bit rate of ADC converter with a programmable amplifier.

Environmental parameters, such as ambient temperature, relative humidity, and barometric pressure are measured with BOSCH's BME280. The sensor manufacturer has provided compensation formulas to ensure the accurate results of the quantities measured [22].

The methods described above are employed for the design (Fig. 1) and manufacture (Fig. 2) of a circuit board accommodating the pins required for the electronic elements and a data recorder with wireless transmission.

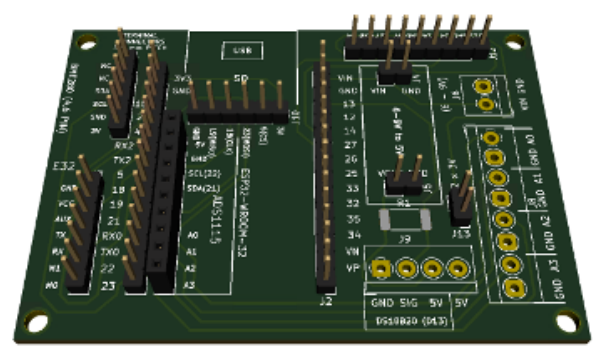

Fig. 1. Design of the data logger with wireless transmission. 

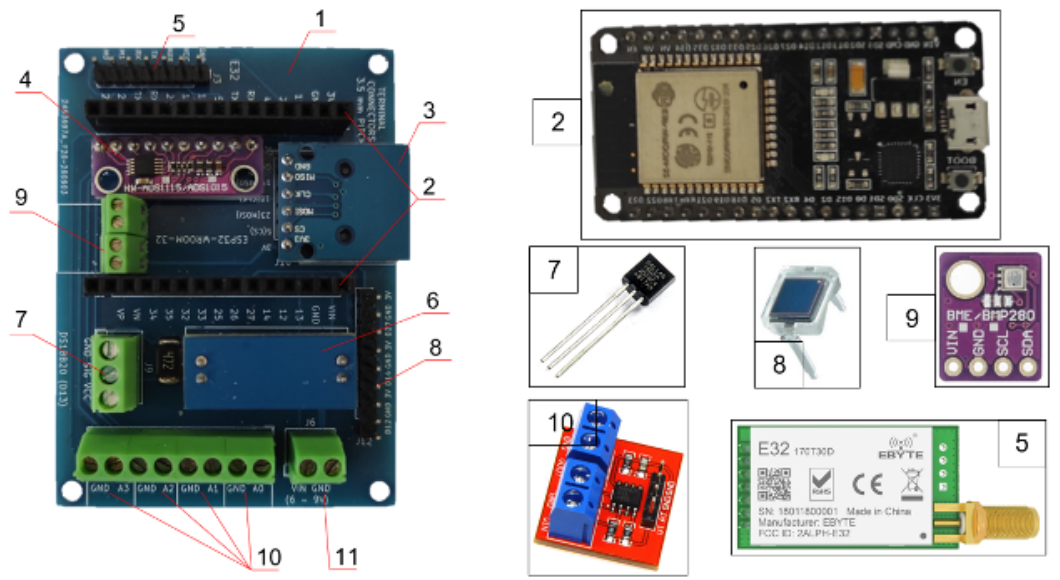

Fig. 2. Prototype board for data recording with wireless transmission: 1) circuit board, 2) microcontroller ESP32 WROOM, 3) SD card slot, 4) four-channel 16-bit analog-to-digital converter (Analog-to-Digital Converters - ADCs), 5) wireless transmitter E32, 6) linear voltage regulator AMS1117, 7) digital temperature sensors, 8) solar radiation sensor BPW34, 9) sensor BME280, 10) voltage and current sensors MAX 471,11) power supply from 6 to $15 \mathrm{~V}$.

\subsection{Materials}

The components used to create the electronic measuring system for the analysis of the photovoltaic panels are shown in the connection diagram in Fig. 3, which consists of the following elements:

- Photovoltaic panels - monocrystalline Pmax $=20 \mathrm{~W}$ and polycrystalline Pmax $=20 \mathrm{~W}$. When choosing the panels, measures are taken to ensure that they are approximately of the same area and overall dimensions of the photovoltaic cells and the frame, from the same manufacturer and one batch. The parameters of the monocrystalline photovoltaic panel at maximum power are: voltage Ump $=18,6 \mathrm{~V}$ and current $\operatorname{Imp}=1,08 \mathrm{~A}$, and with the polycrystalline panel, at maximum power, the voltage is $\mathrm{Ump}=18,2 \mathrm{~V}$ and the current is $\operatorname{Imp}=1,12 \mathrm{~A}$;

- A photovoltaic panel for battery charging - polycrystalline Pmax $=10 \mathrm{~W}$ with maximum power - voltage Ump $=17,4 \mathrm{~V}$ and current $\operatorname{Imp}=0,57 \mathrm{~A}$;

- Digital temperature sensors DS18B20 - 18 pieces -9 pcs installed at the bottom of each photovoltaic panel;

- A rechargeable battery for autonomous operation of a system with voltage $12 \mathrm{~V}$ and current 9 A, placed in the electrical panel;

- A manufactured module with precision-mounted two MAX 471 amplifiers and two consumers (resistances $\mathrm{R}=30,2 \Omega$ ). In this case, the energy produced by the photovoltaic panels is converted into heat energy given out in the electrical panel, which has a ventilation air grille;

- A wireless transmission data logger in the electrical panel;

- A power supply unit with input AC voltage from $\sim 15 \mathrm{~V}$ to $\sim 22 \mathrm{~V}$, output DC voltage from $10 \mathrm{~V}$ to $14 \mathrm{~V}$, and output current up to $3 \mathrm{~A}$. The module is used to switch the power supply to the data logger automatically from the photovoltaic panel or the battery. When the data logger does not consume power, some of it is stored in the battery. The power supply is mounted in the electrical panel; 
- A computer system with internet connection placed in a room at a distance less than 3000 $\mathrm{m}$ and direct visibility with the measurement equipment provides receiving and control of the data.

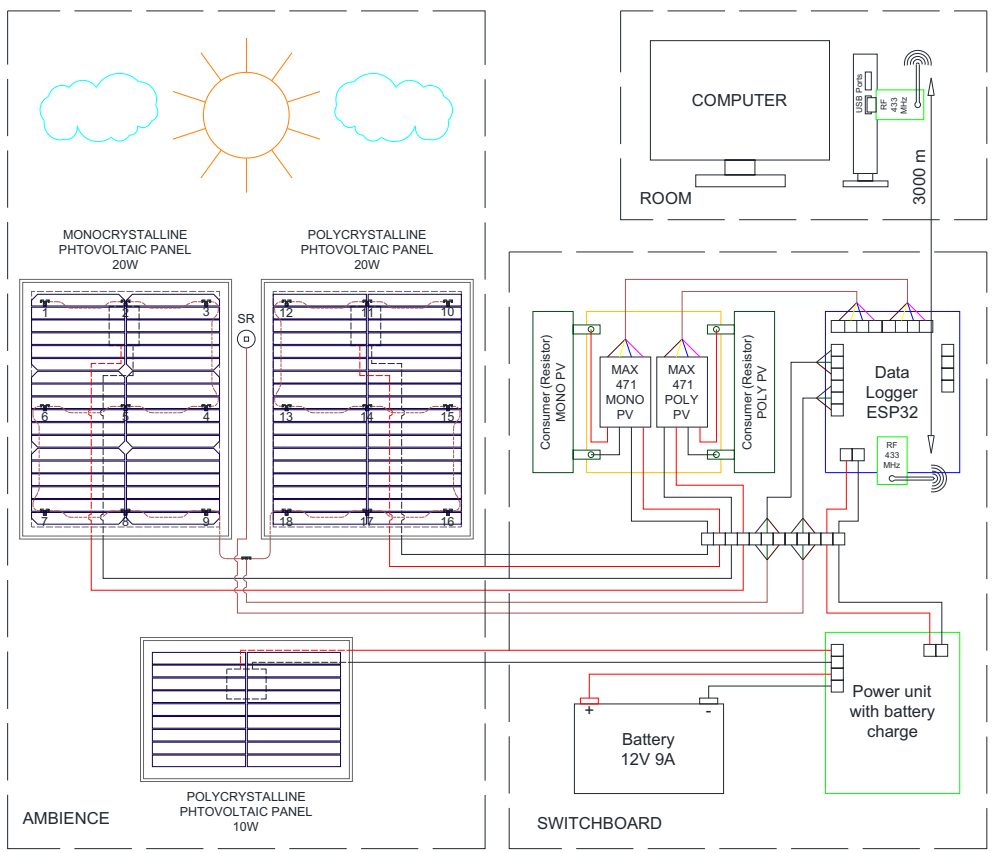

Fig. 3. Diagram of the measuring electronic system for analysis of photovoltaic panels

The created electronic measuring system for analysis of photovoltaic panels is shown in Fig. 4. It is installed on the territory of Technical University - Varna on the university experimental field and oriented to north-south. The installation is accomplished on a steel structure of $\mathrm{L}$ profiles at a height of $1,5 \mathrm{~m}$ and the panels are oriented to the south. The photovoltaic panels fixation is at angle of $32^{\circ}$ to the horizontal plane. The solar radiation sensor is fitted in the same plane as the panels, between them. This aims to ensure its movement to the same angle of the panels after changing the latter.

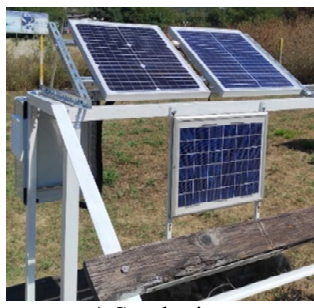

a) South view

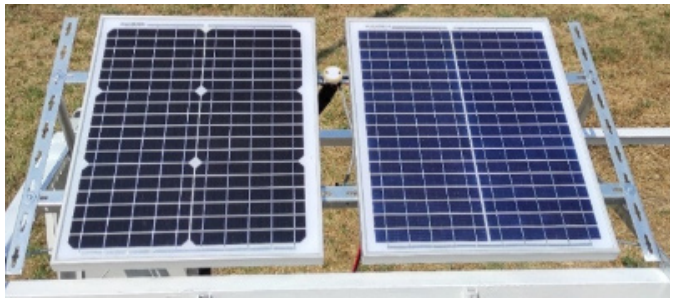

b) Arrangement of the panels on the structure 


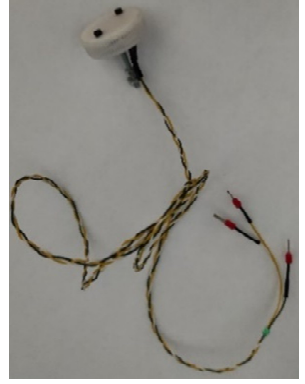

c) Solar radiation sensor

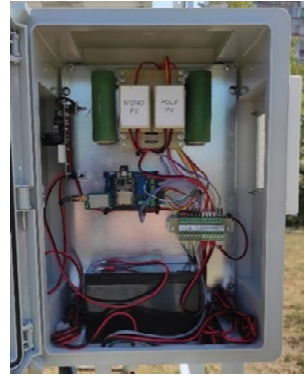

d) Electrical panel with the accommodated elements

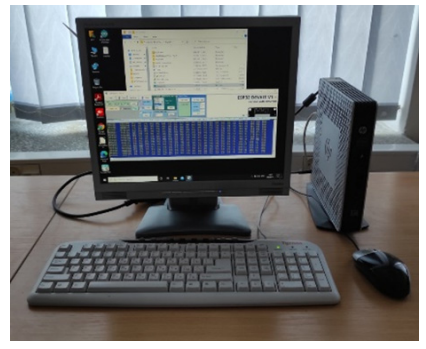

e) Computer and monitor for receiving data from the measuring system

Fig. 4. Photos of the electronic measuring system for photovoltaic panels analysis on the experimental field of Technical University - Varna

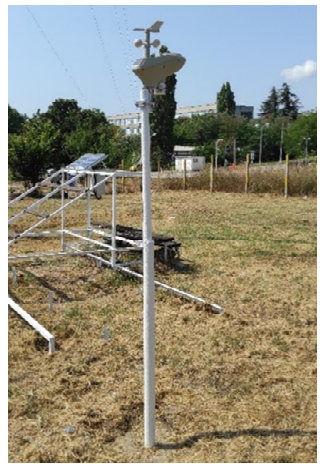

Fig. 5. Meteorological station located in the experimental field of Technical University - Varna

The meteorological station MISOL, model MS-2600-1 is located in the experimental field, $6 \mathrm{~m}$ away from the measuring system. It serves to take readings of the meteorological data required for the analysis of photovoltaic panels. The data obtained are included in the Wunderground global database, and the name under which it can be found on the site is IVARNA50 - Fig. 5.

\section{Results and discussion}

The results obtained are based on the experiments conducted.

The first experiment carried out involves adjustment of the solar radiation sensor and its calculation as per $2.1 K_{S R}$ or the conversion factor calculation. The adjustment has been performed with a standard Kipp \& Zonen CM11B pyranometer in the time range between 11 and 16 hours on a clear day, in every 5 minutes - Fig. 6 a). The conversion factor after processing the data collected is obtained as $K_{S R}=0,572$. Fig. 6 b) illustrates part of the program from the ESP32 microcontroller memory.

The photovoltaic cell areas are constant, the monocrystalline photovoltaic panel being $A_{M}$ $=0,108312 \mathrm{~m}^{2}$, and for the polycrystalline one it is $A_{P}=0,109512 \mathrm{~m}^{2}$. The difference in areas is determined by the geometry of the cells manufactured by different technologies. 


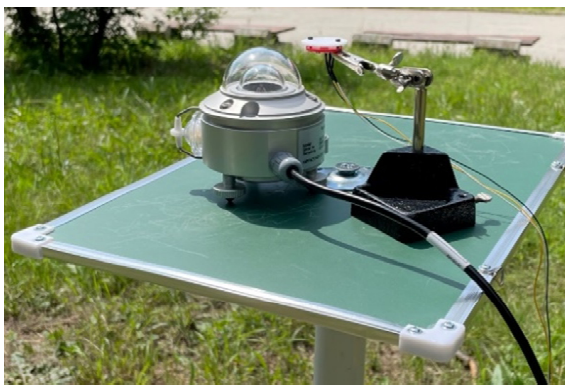

a) Solar radiation sensor adjustment

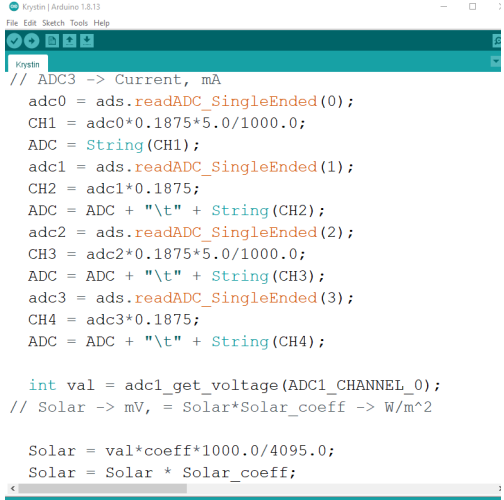

b) Arrangement of the panels on the structure

Fig. 6. Solar radiation sensor adjustment

The second experiment consists of a three-day measurement of the maximum efficiency of the photovoltaic panels in relation to the parameters measured:

$$
\eta=\frac{P}{S R \cdot A}
$$

The time for conducting the experiment is from 01.08.2021 to 03.08.2021 in the time interval from 09:00 to 19:00 hours. The results are recorded every 10 seconds, the measurements are taken every 1 second and when the results of 10 are accumulated, it is averaged and recorded. The readings are presented graphically in Fig. 7, indicating the clear decreasing character of the panel efficiencies at noon. In this case, the more efficient of the two is the monocrystalline panel, which for this period of time achieves an average efficiency of $\eta_{M}=16,06 \%$, and the polycrystalline features an efficiency of $\eta_{P}=14,60 \%$. Fig. 8 presents the results as a function of the temperature relative to the efficiency of the panels for 01.08.2021. The graph indicates that in both types of panels, the efficiency drops after $40^{\circ} \mathrm{C}$.

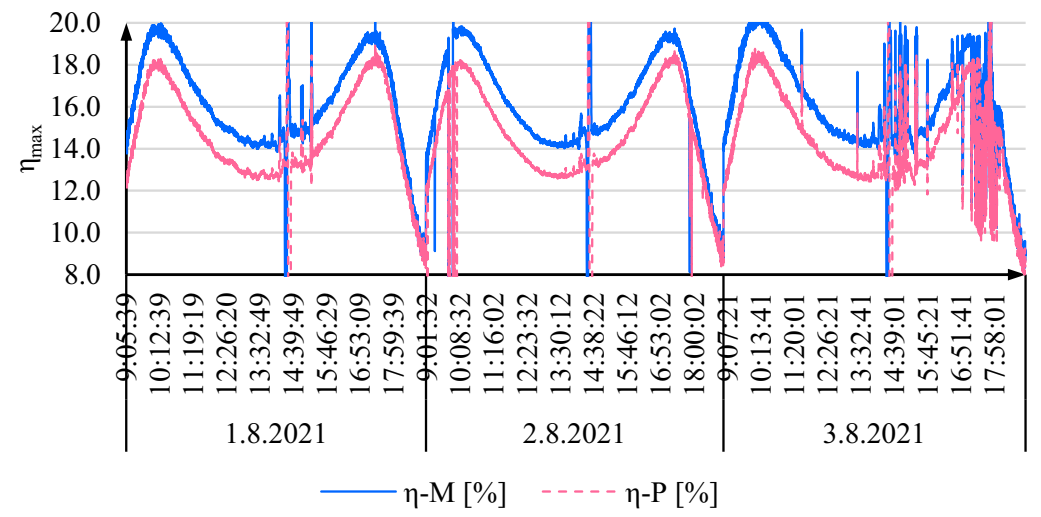

Fig. 7. Efficiency of the panels over the 3 days of the experiment. 


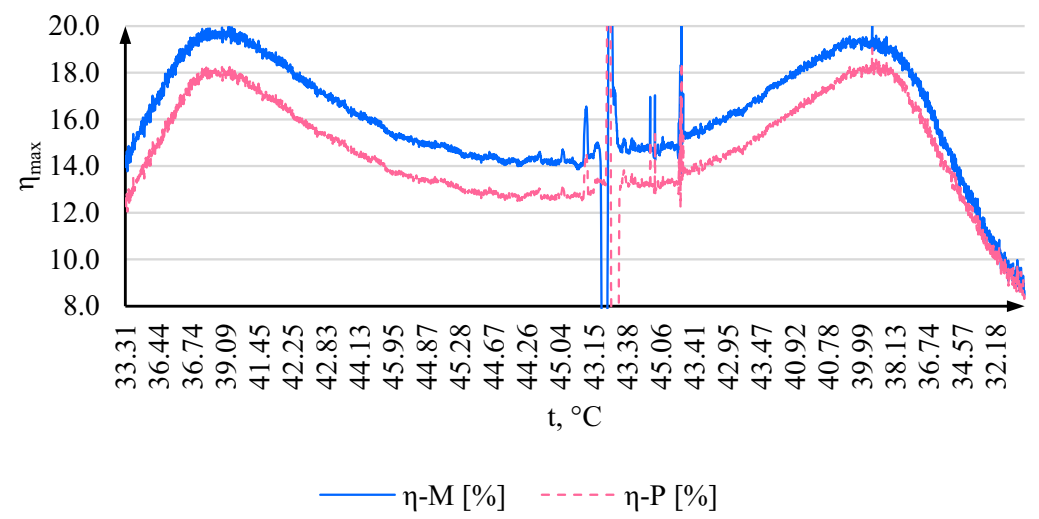

Fig. 8. Efficiency of the panels in relation to their average temperature taken from 9 temperature sensors for 1 day.

The results of the measurements presented in Fig. 7 and Fig. 8 show clearly expressed disturbances. They are simultaneous, or this is the time period from 14:20 to 14:30 hours. This is due to the location of the experimental arrangement near the meteorological mast, which shades first the monocrystalline panel and then the polycrystalline panel. The other disturbances result from clouds in the atmosphere, which are most pronounced on 03.08.2021 in the afternoon.

\section{Conclusions}

1. The electronic measuring system records the data and processes the results in real-time to determine the efficiency and the average surface temperature of a monocrystalline and polycrystalline photovoltaic panels. The results are transmitted properly even at intervals as short as 10 seconds via $433 \mathrm{MHz}$ radiofrequency at a distance of $300 \mathrm{~m}$ with indirect vision. 2. The analysis of the results leads to the conclusion that it is possible to establish the true behavior of the photovoltaic panels efficiency in terms of the temperature they acquire and the environmental parameters during the experiments.

3. The outcomes can be improved and the arrangement can be developed by extending the time for conducting the experiments and taking images of the surface with an infrared camera for comparison with the average contact sensors temperature of the photovoltaic panels underside.

The investigations in that paper have been implemented with the financial support of National Programme "Young scientist and postdoctoral students", funded by Bulgarian Ministry of Education.

\section{References}

1. B. Knopf, P. Nahmmacher, E. Schmid, Energy Policy, 85 (2015)

2. IRENA, Global Renewables Outlook: Energy transformation 2050 (2020)

3. EC, General and regional statistics (Eurostat Database (2020)

4. EC, In focus: Renewable energy in Europe, Energy, (Brussels, 2020) 
5. Eurostat, Electricity production, consumption and market overview (2020)

6. M. Pacesila, S.G. Burcea, S.E. Colesca, Renew. and Sust. En. Rev., 56 (C) (2015)

7. J. Cubas, S. Pindado, C. de Manuel, Energies, 7 (2014)

8. B. Amouche, A. Guessoum, M. Belhamel, Appl. Energy, 91 (2012)

9. M. Catelani, L. Ciani, L. Cristaldi et al., The IEEE Int. ENERGYCON (2012)

10. A.R. Amelia, Y. Irwan, W. Leow et al., Int. J. Adv. Sc., Eng. Inf. Tech., 6 (2016)

11. E. Meyer, International Journal of Photoenergy, art. ID: 8479487 (2017)

12. P.K. Dash and N.C. Gupta, Int. J. of Eng. Res. and Appl., 5 (2015)

13. I. S. Stoyanov, T. B. Iliev, G. Y. Mihaylov and E. P. Ivanova, (ATEE), 2017, pp. 915918, doi: 10.1109/ATEE.2017.7905070.

14. G. Takyi, F. Nyarko, Journal of Power and Energy Engineering, 8 (2020)

15. N. Suwapaet, P. Boonla, Energy Procedia, 52 (2014)

16. Y.M. Irwan, A.R. Amelia, M. Irwanto, et al., Appl. Mech. Materials, 793 (2015)

17. B.K. Indra, Journal of Nepal Physical Society, 3 (2015)

18. G. Sahin. Journal of Basic and Applied Physics, 5 (2016)

19. S. Chander, A. Purohit, A. Sharma et al., Energy Reports, 1 (2015)

20. N. Zlatov, I. Iliev, A. Terziev, V. Kamburova, 15th Int. Workshop on REM, 1 (2014)

21. A. Genbach, D. Bondartsev, I. Iliev, A. Terziev, E3S Web Conf., EENVIRO, 85 (2019)

22. Bosch, Combined humidity and pressure sensor (Germany, 2020) 